sensitive potassium pump at the abluminal membrane of the endothelial cells and relate this to a high concentration of the Na-K-ATPase in these cells compared with that in both non-cerebral endothelial cells and in cerebral cortex as a whole. Brendel and Meezan look critically at the technique for isolating cerebral capillaries and compare the composition of the basement membrane from brain vessels with that from retinal vessels and renal glomeruli.

One is more convinced of the potential of isolated capillaries and cultured endothelial cells as a means of studying control of transport at the blood-brain barrier than as a model for transport across it. Thus, DeBault and Cancilla report intriguing experiments in which the coculture of endothelial cells with glioma cells leads to a maintenance of a high content of $\gamma$-glutamyl transpeptidase in the former. This enzyme is highly specific to cerebral capillaries and the results strengthen the concept that the glial end-feet induce the very particular properties of these vessels. In the same context, Anders and colleagues describe curious "assemblies" of intramembranous particles which occupy the cytoplasmic face of astrocytic plasma membranes. They are particularly numerous in the perivascular membranes of the glial end-feet and could be part of a mechanism for influencing the capillaries.

Isolated capillaries contain adenyl cyclase (as discussed by Palmer and colleagues) and this enzyme is activated by noradrenalin (mainly $\$ 2$ effect), dopamine and in the rabbit by histamine. This possible link in a control of permeability is of particular interest, since cerebral capillaries are contacted by noradrenergic nerve terminals probably originating from cell bodies in the locus coeruleus. The evidence that these control permeability to labelled water independently of any effect on cerebral blood-flow is considered by Hartman and colleagues.

The second section of the book is concerned with perturbation of the barrier and lacks, for me at least, the excitement of the first section. It contains good articles by Nemoto on transport during anaesthesia, by Rapoport on measurement by his new technique of permeability in relation to lipid solubility and of permeability after osmotic shock, and a definitive short review of the blood-brain barrier in acute and chronic hypertension by Johansson.

This book is much better than the usual collection of manuscripts from a symposium. It should be of interest to all those concerned with the blood-brain barrier or with transport across the capillary wall in general. Most particularly, it is valuable as a fairly comprehensive survey of the present state of the art with regard to isolated cerebral capillaries and endothelial cells.

Michael Bradbury is Professor of Physiology at King's College, University of London, and King's College, University of London, and Barrier (Wiley, 1979).

\title{
American Ice Age mammals
}

\section{R.J.G. Savage}

Pleistocene Mammals of North America. By Björn Kurtén and Elaine Anderson. Pp.442. (Columbia University Press: 1980.) \$42.50, £21.20.

BJÖRN Kurtén's Pleistocene Mammals of Europe (Weidenfeld \& Nicolson, 1968) has become a classic; it broke new ground and remains a frequently quoted text. Now the author, in collaboration with Elaine Anderson, presents the Pleistocene Mammals of North America. The format of the new book is similar, but more detailed treatment is given to major sites and their faunas are compared with those of adjacent continents, a useful feature lacking in the earlier work. Although entitled "Pleistocene" mammals, the authors wisely extend their coverage back to include the whole of the Blancan, to a base of around 3.5 million years. Their geographical limits are Canada, the USA and northern Mexico.

In Part I some 250 faunal sites are listed, with notes on geology, geography, ecology and faunal composition. The listing is alphabetical for each state, and the faunas are grouped as Blancan, Irvingtonian and Rancholabrean. There follows a discussion of intercontinental correlation and migrations between North and South America and between North America and Eurasia.

In the second part of the book critical and annotated lists are given for all Blancan and Pleistocene mammal species on the continent. The taxonomic treatment is detailed, giving information on synonymy, geographical and stratigraphical distribution, anatomical characteristics, relationships, evolution, migration and extinction of each species. Some 562 species are treated; extant species are included only where they have a fossil record. The diagnostic features detailed for each species of necessity use highly specialized terms, which however are not explained; e.g. on p.285 a horse species is characterized by having "ectoflexid of lower molars penetrating deeply into the metaconid-metastylid isthmus". In this second section the material ancillary to the text leaves something to be desired. The illustrations depict only a few sample species and the dental characters are not annotated. The quality of the drawings is highly variable; most are taken from the literature without alteration, thus the orientations and scales are often inconsistent and the techniques of drawing differ widely. Further, they are poorly arranged so that there is much wasted space. The maps showing species distribution are clear, though not numerous, and the addition of some reconstructions adds interest, especially for the non-specialist. The tables are important; in Appendix 2 the stratigraphical range of every species is tabulated.
The book is a formidable and scholarly compendium of information: thorough, accurate and up to date. It will be an invaluable reference source for those working not only on Pleistocene faunas, but on problems of evolution, extinction and biogeography. The authors are indeed to be congratulated on so ably treating a colossal mass of data in a digestible and attractive form.

R.J.G. Savage is Reader in Vertebrate Palaeontology at the University of Bristol.

\section{Stone Age summary}

\section{Derek Roe}

Early Man in Britain and Ireland: An Introduction to Palaeolithic and Mesolithic Cultures. By Alex Morrison. Pp.209. (Croom Helm/St Martin's Press: 1980.) Hbk £12.95, \$35; pbk £7.95.

THE Mesolithic period in Britain lasts for around 5,000 years, the Palaeolithic for perhaps 500,000 . Books on British archaeology seem to be produced in an inverse relationship to the durations of the successive periods. Lavishly illustrated information on Saxons, Vikings, Romans or Iron Age groups beckons from every shelf, but the choice is limited for those trying to study Early Man in Britain. Clearly, Alex Morrison's book meets a real need and let us hope the reading public will think so as well as teachers and students of archaeology, because early Prehistory in Britain, however unspectacular by comparison with, say, its equivalent in East Africa, has considerable fascination and importance in an Old World context.

That, however, does not make it an easy subject for a book. Sites exist in thousands, but the material from them is widely scattered; dating, for the Palaeolithic, is extremely difficult, and relatively few fully documented modern excavations have taken place. Undisturbed sites are rare: usually all fragile objects and much of the environmental evidence has gone. The British Mesolithic is a little better off in these respects, but even here the situation is far from ideal. For broad interpretation, one needs to know much about the Palaeolithic and Mesolithic of continental Europe: the geographical situation of Britain positively demands this, as $\mathrm{Mr}$ Morrison rightly stresses.

In these circumstances, one can either set out to write a massive book on the Palaeolithic and another on the Mesolithic, each based on exhaustive first-hand study of the extant material, or one can produce an outline summary, based almost entirely. on the literature. Alex Morrison has opted 